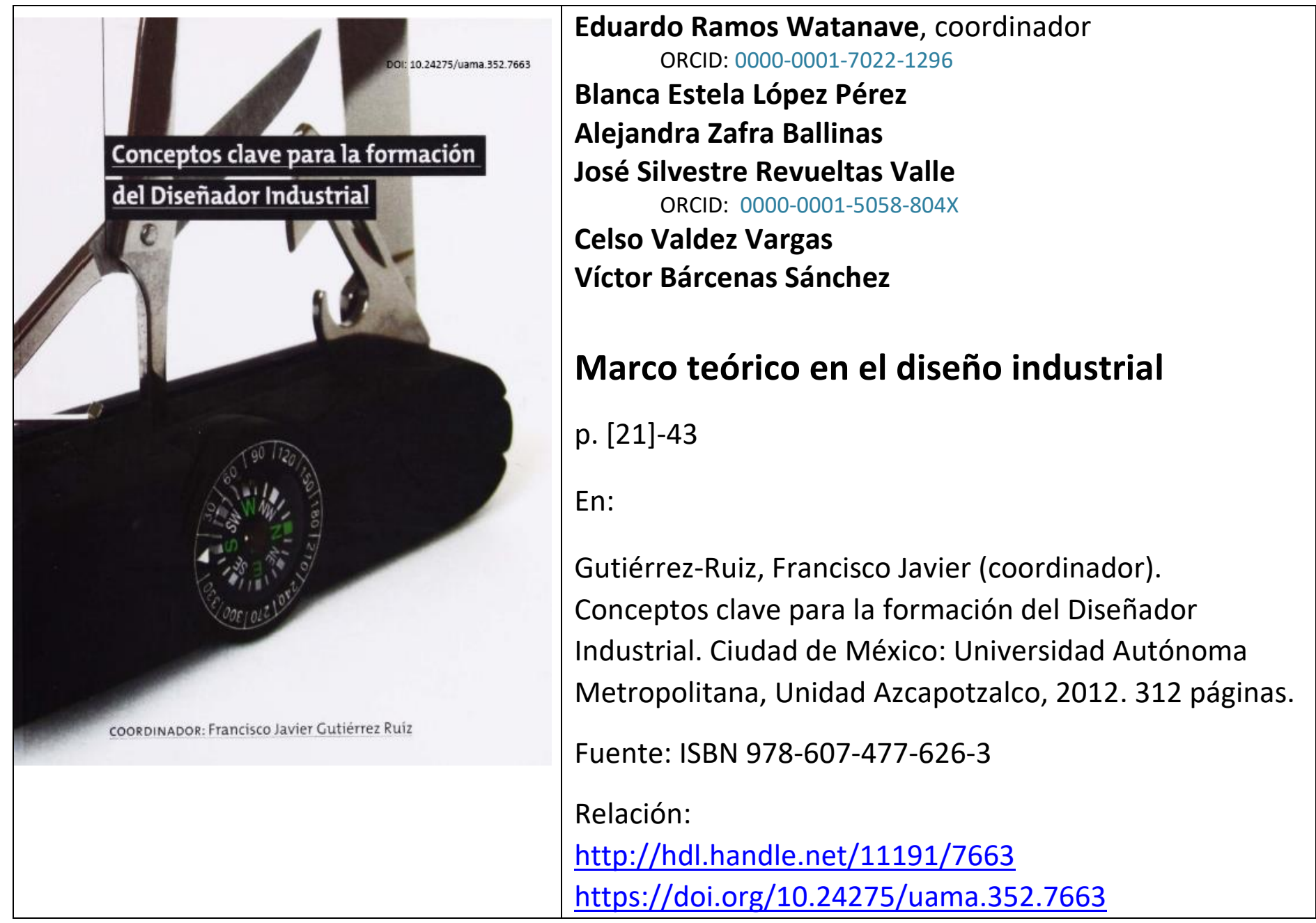

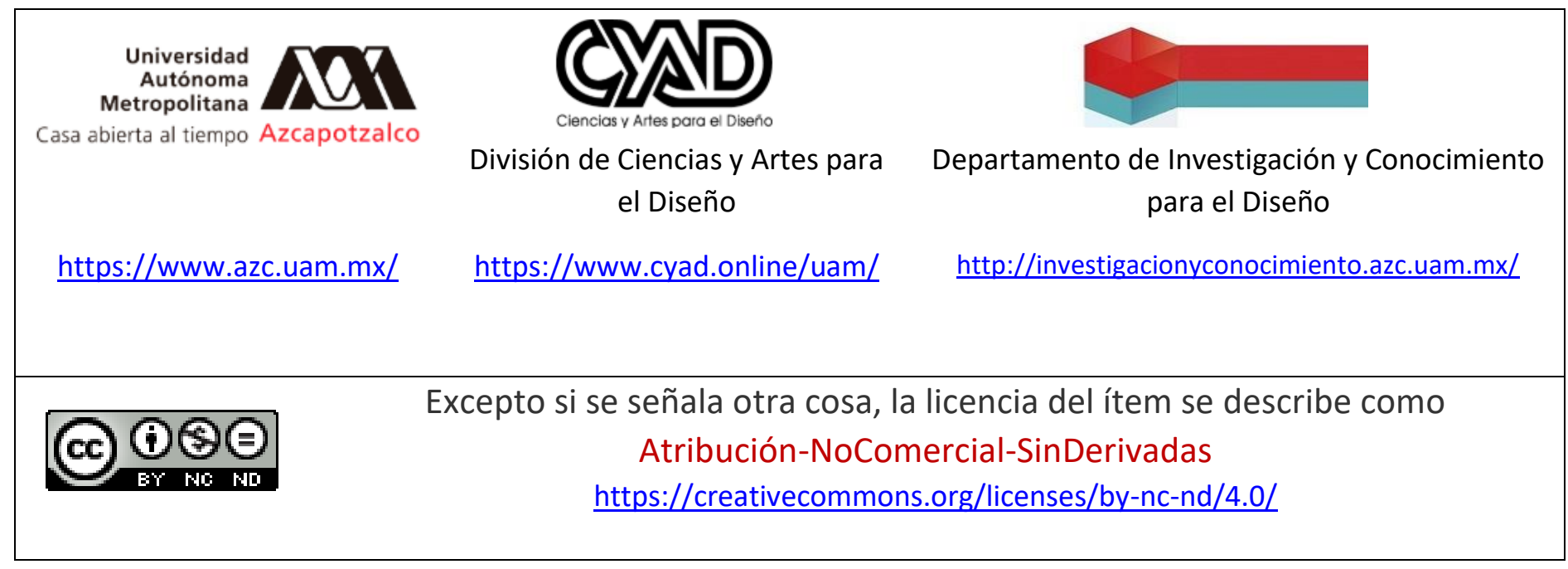

D.R. (C) 2012. Universidad Autónoma Metropolitana. Unidad Azcapotzalco (UAM Azcapotzalco). Se autoriza copiar y redistribuir el material en cualquier medio o formato, siempre y cuando se den los créditos de manera adecuada, no puede hacer uso del material con propósitos comerciales, si remezcla, transforma o crea a partir del material, no podrá distribuir el material modificado. Para cualquier otro uso, se requiere autorización expresa de la UAM Azcapotzalco. 
- Análisis

- Concepto

- Conocimiento

- Contexto

- Diseño

- Fenómeno

- Lenguaje

- Objetivo

- Objeto

- Relación

- Sujeto

- Teoría 
DOI: $10.24275 /$ uama. 7048.7668

DESARROLLO DE CONCEPTOS POR:

DI. Eduardo Ramos Watanave (Coordinador)

MTRA. Blanca Estela López Pérez

MTRA. Alejandra Zafra Ballinas

DR. José Silvestre Revueltas Valle

ARO. Celso Valdez Vargas

ARO. Víctor Bárcenas Sánchez

Profesores-Investigadores del Departamento

de Investigación y Conocimiento para el

Diseño, UAM-Azc./ División CyAD 


\section{Marco teórico en \\ el diseño industrial}

\author{
"Quisiera partir de la hipótesis, quizá arriesgada pero \\ extraordinariamente fértil, de que la teoría del diseño es \\ la más auténtica teoría de los objetos, la mejor ciencia de \\ los artefactos entre las cuales podemos disponer hoy".
}

\section{Fundamentación y concepción del discurso}

A la teoría la han definido diferentes autores como ese conjunto de conocimientos que le permiten a cualquier persona explicar y explicarse la realidad tangible, el mundo que le rodea o dicho en otras palabras, los fenómenos que surgen en el universo perceptual; de hecho ese es uno de los usos más frecuentes que tiene la teoría, sin embargo, el significado original de la palabra, como casi todos los términos en la lengua castellana, proviene de raíces griegas y latinas. Para los griegos había una distinción entre ese ver con los ojos que nombraron orein, y el ver con el interior que llamaron theorein (García, 1996:132), este último se manifiesta cuando se producen en el ser humano los fenómenos al chocar con la realidad tangible, es decir, al captar un sabor, un olor, un sonido, una imagen o una señal táctil aparecen en nosotros hechos de los cuales hacemos conciencia, esta última es fundamento de la experiencia. En resumen, del término griego theorein se deriva el término teoría, que no es otra cosa que ese ver con el ser interior que todo ser humano tiene y que construye día con día, por eso cuando alguien habla de un tema o se aprecia alguna realidad especifica existe la posibilidad de entenderla y poder explicarla gracias a la empiría, esta última no es otra cosa que lo que sucede en uno cuando se tiene el contacto con el mundo exterior y dura en uno la visión de dicho fenómeno.
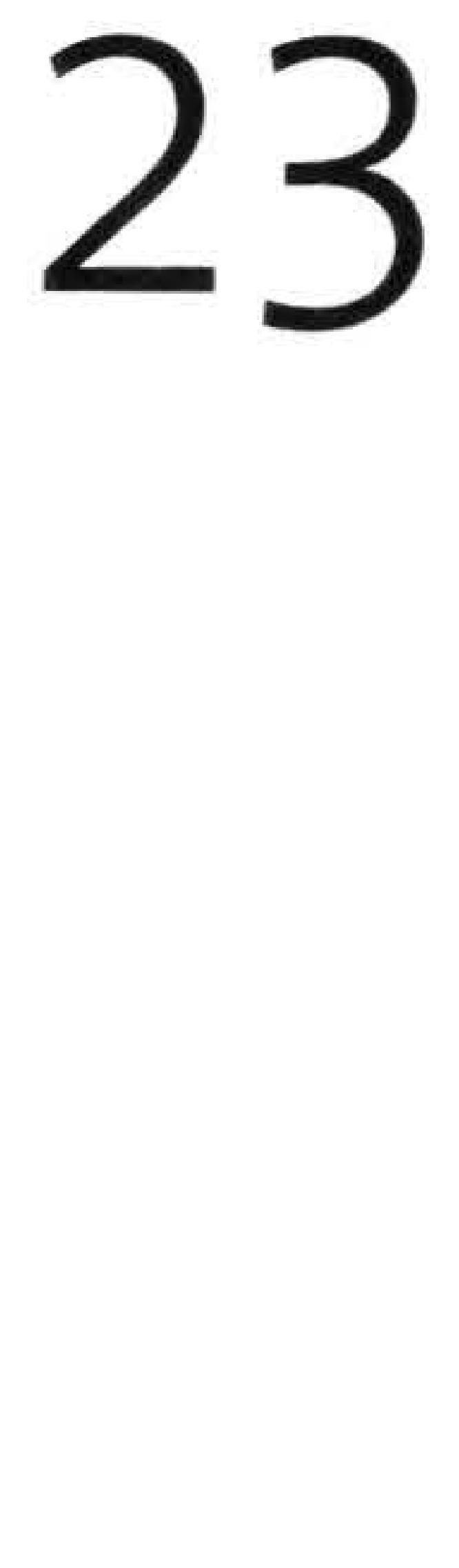

1. Fernández, Silvia; Bonsiepe, Gui y Ricini, Raimonda, "Diseño y teorías de los objetos", en Historia del diseño en América Latina y el Caribe, Brasil, Blücher, 2008, p. 292 
2. "Las llamadas necesidades son categorías conceptuales producto de la combinatoria inagotable de percepciones, creencias, habilidades y destrezas que en lo cotidiano confrontamos" (Martín Juez, 2002:53)

3. "El concepto cultura material es una idea influyente y restrictiva del lugar que ocupa el objeto en la cultura. El término material -llamamos material a aquello que "cosificamos"— suele asociarse a la caracterización del objeto en oposición a lo espiritual, a lo mental, a lo que tiene alma y se entiende en correspondencia univoca con el sujeto, con lo vivo y humano", (Martin Juez, Idem:38).

4. "El objeto no es solamente útil, es también una idea. Una prótesis buena para usar y una metáfora buena para pensar" (Martín Juez, Idem:96)
Con lo anterior se puede concluir que la teoría tiene un papel fundamental en cualquier campo de conocimientos ya que con ella se asimila la realidad, se construye el discurso (Martín 2002:58), se realizan planteamientos, se estructura el pensamiento, además sirve para ejecutar acciones operativas, tomar decisiones, imaginar futuros posibles; se puede decir que la teoría es para el conocimiento lo que la práctica es para el proyecto.

Ahora bien, el lenguaje es un elemento central en la construcción del discurso teórico proyectual, no puede haber teoría sin discurso y tampoco hay discurso sin una postura ante el hecho o sin una cosmovisión, es decir, una orientación de cómo vemos el mundo o qué idea tenemos de él. La teoría se manifiesta con un lenguaje específico en cada uno de los diferentes campos disciplinares ya que cada área del conocimiento presenta sus propios conceptos. El concepto es la idea más general que explica el hecho, también se le concibe como una proposición cerrada, o un párrafo en donde su opuesto siempre tiene un valor falso. Ya sea el término o la oración que abarca la mayor generalidad posible de entendimiento y que permite explicar y entender el fenómeno, es lo que se considera el concepto.

En el campo del diseño, y por la propia naturaleza del trabajo disciplinar, los conceptos que se construyen y que son propios del discurso proyectual, son los sistemas que generan formas estéticas, formas perceptuales que satisfacen necesidades, ${ }^{2}$ que solucionan problemas antropológicos, que conforman la cultura material ${ }^{3} \mathrm{y}$ que por supuesto abonan al conocimiento del diseño. Por eso al nombrar distintos objetos 4 como: silla, mesa, sofá, estufa, refrigerador, plancha, ordenador, escritorio, radio, grabadora, entre muchos otros que rodean la vida cotidiana de nosotros los humanos, no sólo nos referimos a la cosa tangible, material y presente, también nos referimos a la idea, al concepto, al sistema, a la imagen que formamos mentalmente y que tiene para nosotros una estructura y una apariencia exterior, una figura que nos posibilita si ya existe, o posibilitará en el porvenir la estética y con ello la asignación de significados según la circunstancia en que se encuentre.

\section{El marco teórico proyectual}

En su libro Contra un diseño dependiente, Enrique Dussel explica sobre el marco teórico lo siguiente: "El marco teórico proyectual es un conjunto de criterios operativos de integración interdisciplinaria que le permite tener al 
diseñador, siempre a la mano, criterios poiéticos o productivos que le sirvan para discernir lo que tiene entre manos" (Gutiérrez, De Antuñano, Dussel, et al, 1977:65). Desde este punto de vista el marco teórico está conformado en distintas categorias que abarcan criterios de ubicación, de temporalidad, de procedimiento, de ideología, de organización, etc., por ejemplo, se encuentran los aspectos administrativos que deben considerarse para el diseño de un producto, los factores tecnológico-productivos para hacer factible su realización, también los elementos culturales y sociales que permitirán su aceptación por parte de los usuarios, las condiciones de espacio físico en donde se ubicará el objeto diseñado, el momento en el cual se pretende comercializar, así como también las circunstancias no menos importantes que deben tenerse en cuenta para hacer posible el proceso de diseño, como son: la situación económica y las circunstancias políticas del país o región, tanto de elaboración como de destino del producto, condiciones ambientales, culturales y sociales que determinan los limites en los cuales se debe diseñar.

La configuración del marco teórico nos establece el caso de estudio a partir de diferentes abstracciones de la realidad y mediante distintas técnicas de recopilación de información como son: la observación directa del fenómeno, las entrevistas y las encuestas que forman un panorama de lo que aprecian quienes se encuentran inmersos en el asunto, también se emplean recurrentemente el levantamiento de datos y la compilación de información documental como hechos históricos, tanto en imágenes como en texto.

Entonces, se tiene un caso definido cuando se han localizado las distintas manifestaciones de la realidad con las cuales se logra sustentar el comportamiento del fenómeno de estudio; es aquí donde se deben hacer presentes los métodos y las técnicas que auxiliarán al diseñador para transformar la información en abstracciones que sean útiles para efectuar la práctica proyectual, es decir, pasar de lo puramente teórico a lo estrictamente práctico, pasar del concepto al precepto, pasar de una realidad inteligible a una realidad tangible, considerando siempre que en el diseño se transforma constantemente ${ }^{5}$ y que cada caso es particular, por lo cual no es factible la construcción de marcos teóricos generales.

La interdisciplinariedad real implica la existencia de varias especialidades autónomas, sería inconcebible una disciplina que se defina
5. "Lo que quiero destacar aqui es que el diseño no es un objeto que pueda ser clasificado con la precisión con la que pueden serlo las mariposas. El diseño es una actividad que cambia constantemente. Entonces ¿cómo podemos establecer un cuerpo de conocimientos respecto de algo que no tiene identidad definida?" (Margolin Victor, 2002:314). 
como tal, asumiendo conocimientos, métodos, etc. de otras ramas de la ciencia. El diseño, sin duda, ha tenido desde un principio grandes dificultades para crearse una identidad especifica en cuya base pudiera tener lugar interacciones con otras disciplinas (Bürdek, E., 1994:175).

Eduardo Ramos Watanave

\section{Bibliografía}

BerTHIER, A. Emmanuel (2004), ¿Cómo construir un marco teórico?, Material para el taller de elaboración de proyectos, Módulo II, Investigación documental y marco teórico, julio de 2004 .

BÜRDEK, E. Bernhard (1994), Diseño. Historia, teoria y práctica del diseño industrial, México: Gustavo Gili.

FERNÁNDEZ, Silvia y Bonsiepe, Gui (2008), Historia del diseño en América Latina y el Caribe, Brasil: Editora Blücher.

GARCía Olvera, Francisco (1996), Reflexiones sobre el diseño, México: UAM-Azc., Colección CyAD.

GutiérRez M.L., De Antuñano, J.S., Dussel E., et. al. (1977), Contra un diseño dependiente: Un modelo para la autodeterminación nacional, México: Edicol. MARGolín, Victor (2002), Las politicas de lo artificial, México: Designio.

MARTín Juez, Fernando (2002), Contribuciones para una antropologia del diseño, España: Gedisa. 


\section{Análisis}

\section{Definición Diccionario RAE (DENOtACIÓN)}

Distinción y separación de las partes de un todo hasta llegar a conocer sus principios o elementos. Examen que se hace de una obra, de un escrito o de cualquier realidad susceptible de estudio intelectual. Examen de los componentes del discurso y de sus respectivas propiedades y funciones.

\section{DESARROLLO O CONSTRUCCIÓN DEL CONCEPTO}

Para descubrir el sentido original y propio del análisis, hay que partir de la lengua donde se originó y usó: el griego clásico. El término analysis - nombre verbal de analyein - aludía a: desatar, desligar, disolver, reducir a sus elementos, examinar en detalle, resolver un problema, desatar un nudo, destruir, abolir una ley y también levantar el ancla, romper las cadenas, desamarrarse, arrepentirse y partir. En todos esos significados está la idea de separar lo que estaba unido, de liberar las ataduras.

Analysis, nombra a la acción y al resultado de la acción que expresa el verbo analyein y por lo mismo dice: desatadura, desligamiento, liberación, descomposición, solución, sección, partición, división, separación.

Opuesto a analysis es synthesis, que es su correlativo.

El término griego analysis pasa a las lenguas vivas actuales -ligeramente modificado en sus gráficos literales-, con sus diferentes significados, predominando el que sigue su construcción literal.
El verbo analyein está compuesto del prefijo ana, an, que en composición añade las ideas: de abajo a arriba, de hacer otra vez, de hacia atrás y de hacer lo contrario, y del verbo alyein cuyo nombre verbal álytos significa lo que no se puede desatar, lo que no se puede disolver, lo no liberado, lo indisoluble, por lo que el verbo analyein, dice en primera instancia descomponer un todo en sus elementos y analysis nombra a la acción y al resultado que expresa el verbo, es decir, la descomposición, la disolución de un uno compuesto en sus componentes.

\section{USOS O ACEPCIONES (ACLARACIONES)}

Los análisis en el diseño siguen el mismo concepto ya expresado, se realizan para conocer las características de los objetos mediante la separación, el desligue, la disolución del objeto todo en sus componentes básicos. En la práctica se pueden desarrollar análisis con propósitos diversos, ya sea para conocer las funciones de cada subsistema y de cada pieza componente del producto, por ejemplo: si la función de la parte componente es empujar o jalar, deformar o soportar, guiar, sellar, etc., si se trata de funciones físicas o mecánicas; o también pueden requerirse de análisis para funciones psíquicas, por ejemplo, para saber si la función del elemento es informar, alertar, educar, etc.

También se pueden realizar análisis para estimar la manera como trabaja cada elemento componente en la estructura completa de un producto, por ejemplo: si las partes trabajan a cargas mecánicas de presión, tensión, flexión, torsión o cargas de corte; asimismo pueden 
ejecutarse análisis cuyos fines sean para la manufactura del producto, tanto para entender las geometrías y los acabados, como para asimilar las relaciones funcionales entre las piezas y decidir el proceso más conveniente en su fabricación y ensamblaje, por ejemplo: si el exterior de la pieza es cilíndrico, podría optarse por un proceso de torneado, si fuera hueco por un proceso como el fresado, el taladrado o incluso la fundición, o troquelado, dependiendo de la cantidad de piezas a fabricar, de los materiales a emplear y de las especificaciones técnicas principalmente, entre muchos otros propósitos que en la disciplina del diseño se requieren conocer.

Algunas otras intenciones del análisis en la práctica del diseño son: ubicar al futuro producto en un contexto, en este caso lo que se analiza son las circunstancias en las cuales se puede encontrar el producto en el trabajo real, por ejemplo: los colores que predominan en el lugar de destino para que el objeto se integre estéticamente al lugar, el tipo de suelo para su instalación (concreto, tierra, pasto $u$ otro), las diferentes formas para su fijación al piso, o también las condiciones de humedad y calor a las que se someterá durante su funcionamiento, con el propósito de decidir sobre los materiales de construcción del producto. Si fuera para una zona costera con mucha humedad y salinidad, cuyo clima sea muy caliente, se deberá evitar el uso de materiales que se oxiden con facilidad o que se deformen rápidamente con el calor.

También se pueden realizar análisis para conocer sobre la competencia del futuro producto, por ejemplo: entender sobre las ventajas y desventajas que debe superar o evitar en el precio, desempeño, durabilidad, garantías, etc., del mercado destino, entre muchos otros propósitos que tienen los análisis en la disciplina del diseño industrial.

\section{SiNónIMOS}

Correlación, correspondencia, vínculo, nexo, ligazón, ilación, concomitancia, concordancia.

\section{ANTÓNIMOS}

Desconexión, independencia.

\section{EJEMPLOS}

Análisis estructurales para valorar: resistencia, durabilidad y comportamiento del producto.

Análisis diagnósticos para conocer el desempeño del producto durante el uso.

Análisis de los materiales para la fabricación del producto, para valorar la resistencia y durabilidad.

Análisis de los volúmenes envolventes del producto (análisis morfológico), tanto para realizar nuevas propuestas de diseño, como para valorar aspectos de fabricación, ensamblaje $o$ de envase y embalaje.

Análisis de las funciones del producto para desarrollar las especificaciones técnicas 


\section{Concepto}

\section{Definición Diccionario RAE (DENOtACIÓN)}

Idea que concibe o forma el entendimiento. Pensamiento expresado con palabras. Sentencia, agudeza, dicho ingenioso. Opinión, juicio.

El concepto puede referirse también al acto de determinar algo en la mente después de examinadas las circunstancias.

\section{DESARROLLO O CONSTRUCCIÓN DEL CONCEPTO}

En general, todo procedimiento que posibilite la descripción, la clasificación y la previsión de los objetos cognoscibles se entiende como conceptualización. Entendido de tal manera, el término tiene un significado muy general y puede incluir toda especie de signo o procedimiento semántico, cualquiera que sea el objeto (abstracto o concreto), al que se refiera.

También se trata de una idea simple o de una idea general.

Se entiende como una proposición cerrada (debido a que su opuesto siempre es falso), por ejemplo: El Everest es una montaña, verdadero; El Everest no es una montaña.

Se trata de una unidad de significado.

En el campo del diseño el concepto queda determinado por el Sistema, entendido éste como la unidad mínima de significado en la construcción de un producto funcionalmente útil.

\section{USOS O ACEPCIONES (ACLARACIONES)}

Formación de conceptos: invención, definición o elucidación de conceptos.
El concepto como esencia, en el pensamiento clásico, refiere a aquellos rasgos que son constitutivos del objeto mismo y que no son alterados por la perspectiva con la que dicho objeto es abordado.

El concepto como signo del objeto, según los estoicos, es el que se encuentra en una relación de significación con el objeto (real o abstracto), es decir, no son sujetos de ser experimentados como fenómeno empírico y tampoco guardan semejanza sensorialmente perceptible con los objetos a los que refiere. Son instrumentos de previsión en el contexto de una teoría.

El concepto, no es el término, sino una relación de significado/signo/objeto, es decir, relación de significación.

En el ejercicio del diseño las ideas iniciales generadas para la solución de un problema previamente definido, forman el principio básico de la conceptualización, por ejemplo: al proponer algunas soluciones que se sustenten en acciones como golpear, saltar o caminar; se tendrían como conceptos:

Para golpear: contacto físico entre dos cuerpos, impactos para deformar, dañar algo, lastimar a un cuerpo, etc.

Para saltar se podría pensar en ideas como: despegarse de la superficie de soporte, impulsar a un cuerpo hacia arriba, evitar un obstáculo, etc.

Para caminar: secuencia de pasos, frecuencia, ritmo, movimiento, etc.

En estos tres ejemplos los mismos términos que describen acciones son entendidos como conceptos: golpear, caminar, saltar son ideas generales, son unidades de significado. A su vez, 
con estas ideas iniciales expresadas lingüísticamente se pueden empezar a trabajar las representaciones gráficas (conceptos gráficos), para que paulatinamente evolucionen conforme avance el proceso de diseño.

Al nombrar a los objetos de diseño, nos referimos a su sistema y por extensión a su concepto, por ejemplo: silla, mesa, banco, sofá, teléfono, refrigerador, automóvil, son sistemas y también cada uno es un concepto, cada persona tiene en su mente lo que es una silla, lo que es una mesa, lo que es un automóvil porque lo entiende, porque le significa.

\section{SINÓNIMOS}

Idea, noción, representación, abstracción, aprehensión.

\section{ANTÓNIMOS}

Programa, proyecto, plan, sistema y método (hay que observar que estos términos comprenden pluralidad y extensión, frente a las características primordiales del "concepto" que son singularidad y restricción a una unidad de significado).

\section{EJEMPLOS}

Diseño orgánico, este concepto basa sus características formales en la línea y la superficie curva, y en la unidad de todos sus elementos.

Diseño racionalista, es una idea del diseño formal que concentra sus principios constructivos en las figuras geométricas básicas (círculo, triángulo y cuadrado), y en los colores primarios (amarillo, rojo y azul o amarillo, cian y magenta, más el blanco y el negro con las escalas del gris).

Diseño posmoderno, concepto generado durante los últimos años de la década de los 50 , basa sus principios en la idea de acercar el arte a las clases populares (Diseño Pop), asimismo se fortalece durante los años sesenta fundamentándose en la burla y la ironía.

\section{Conocimiento}

\section{DEFINiCión Diccionario RAE (DENOTACIÓN)}

Acción y efecto de conocer. Entendimiento, inteligencia, razón natural. Cada una de las facultades sensoriales del hombre en la medida en que están activas.

\section{DESARROLLO O CONSTRUCCIÓN DEL CONCEPTO}

El problema del conocimiento ha sido objeto de una disciplina filosófica llamada teoría del conocimiento, gnoseología o epistemología.

El conocimiento es la significación de un objeto de estudio realizado por un sujeto cognoscente que aprehende dicho objeto. Al aprehender el objeto, el sujeto lo hace de manera gnoseológica, es decir, representativamente. Cuando lo representa tal como el objeto es, el sujeto tiene un conocimiento verdadero (si bien posiblemente parcial) del objeto; cuando no lo representa tal como es, el sujeto tiene un conocimiento falso del objeto.

El conocimiento es, por tanto, toda relación de saber del sujeto sobre su objeto, es su fenomenología, es decir, su fenómeno convertido en objeto 
de su conciencia, es la apariencia trascendida. Todo conocimiento en su origen es considerado como mera posibilidad, en tanto que nunca estaremos seguros de llegar a su total conocimiento verdadero, sólo a su aproximación. Todo conocimiento es posible, pero no de un modo absoluto, sino únicamente de manera relativa.

Conocer, es saber que eso que está frente a mi, es tal como lo estoy pensando.

El conocimiento en la disciplina del diseño industrial puede estar contenido en una filosofía, una teoría o una poética, mediante el desarrollo de sus principios, fundamentos o supuestos, categorías y naturaleza de su propio campo del saber al que corresponde.

\section{USOS O ACEPCIONES (ACLARACIONES)}

Todo conocimiento implica una fenomenología acerca del saber, en el que el conocimiento se construye como relación del saber entre el sujeto que aprehende denominado "sujeto cognoscente" y su objeto que pretende ser aprehendido llamado "sujeto cognoscible" que contiene los datos y la información al que el sujeto accederá, organizará, recortará, sistematizará e interpretará.

En el campo del diseño el conocimiento sirve para proponer nuevos satisfactores de necesidades y resolver problemas cotidianos del ser humano, por ejemplo: al plantearse una situación de necesidad de refugio en la que existe la problemática de insuficiencia de espacio habitable, tendrían que conocerse los diferentes factores que provocan el problema, entre los que se pueden encontrar: el número de habitantes estimado, el tipo de actividades que se prevé realizarán en el refugio, el tipo de habitante y sus características, entre otros. Para dar solución al problema debe tenerse el conocimiento y no sólo creer o imaginar qué se sabe sobre los factores que lo provocan.

Otro ejemplo lo tenemos cuando se ha efectuado el diseño conceptual y llega el momento de realizarlo, de llevarlo a la realidad tridimensional, para esto es necesario saber con qué procesos y materiales se podrá fabricar, cuáles son las posibilidades de obtención geométrica que da cada máquina y cada herramienta, así como también, saber cuáles son los materiales más adecuados que generen la resistencia y los acabados esperados. Para esto es importante conocer sobre procesos de manufactura.

\section{SINÓNIMOS}

Juicio, saber, clarividencia, criterio, raciocinio, razonamiento, reflexión, comprensión.

\section{ANTÓNIMOS}

Irreflexión, desacierto, ignorancia, desconocimiento.

\section{EJEMPLOS}

Existe el conocimiento empírico sobre el entorno del diseño, que se da con base en la observación o experimentación de la vida cotidiana. Para el diseñador es fundamental entender cómo los usuarios efectúan sus actividades antes de realizar propuestas de solución. Por ejemplo: si el diseñador no ha tenido la experiencia de elaborar una ensalada, que implica hacer distintos cortes de legumbres, difícilmente 
podrá sugerir el diseño de algún utensilio para rebanar, picar o rajar alimentos.

Otro tipo de conocimiento en el diseño es el científico, éste se genera principalmente a través de la documentación y/o experimentación ordenada, para desarrollar teorías, métodos, técnicas o incluso tecnologías; por ejemplo: al realizar entrevistas y/o encuestas a clientes o usuarios potenciales de un futuro producto, o sobre productos de la competencia para conocer opiniones y juicios, y así tomar decisiones sobre las características para el diseño del objeto, lo que se genera es la información documentada, que en sí misma contiene conocimiento científico.

El conocimiento intuitivo es muy recurrente en el diseño, debido principalmente a la gran influencia que tiene del arte plástico, en el que la expresividad se encuentra sobre lo estrictamente racional, cuantificable y verificable. Un ejemplo de este conocimiento se da en la usabilidad de los objetos mediante el trabajo simbólico del producto para que sea comprendido intuitivamente por el usuario, con este conocimiento no existe la necesidad de leer un instructivo y tampoco hay que tener una experiencia anterior, sólo por intuición se sabe como funciona y como se usa.

\section{Contexto}

\section{Definición Diccionario RAE (DEnotación)}

Entorno lingüístico del cual depende el sentido y el valor de una palabra, frase o fragmento considerados. Entorno físico o de situación, ya sea político, histórico, cultural o de cualquier otra índole, en el cual se considera un hecho. Orden de composición o tejido de un discurso, de una narración, etc. Enredo, maraña o unión de cosas que se enlazan y entretejen.

\section{DESARROLLO O CONSTRUCCIÓN DEL CONCEPTO}

Orden de composición o tejido de ciertas obras. Serie del discurso, tejido de la narración, hilo de la historia.

En el uso de las palabras de los libros sagrados para probar los dogmas de la religión católica es de suma trascendencia el conocimiento del contexto del lugar de donde se toman, sólo conociendo el contexto se podrá dar a las mismas su verdadero sentido literal.

\section{USOS O ACEPCIONES (ACLARACIONES)}

Se usa para definir distintos niveles de la realidad y su disposición para determinados procesos, por ejemplo: el diseño industrial y su contexto nacional.

En el campo del diseño el término contexto se usa para hacer la descripción de las condiciones alrededor de las cuales se encuentra: la necesidad, el problema, el usuario, los factores de producción, el medio ambiente en el que se está trabajando, etc., por ejemplo, cuando se establece la frase: "el diseño de un producto destinado al contexto nacional", se refiere a que el diseñador debe conocer y describir qué tan bien o qué tan mal se encuentra la economía, la tecnología, la educación; incluso es muy útil hacer la descripción de la situación ambiental (tipo de vegetación, tipo de suelo, los porcentajes de humedad, 
velocidad de los vientos, etc.) o cuando se refiere a la situación tecnológica, el contexto se establece con la descripción de la maquinaria, herramientas, materiales, métodos y técnicas usadas para la fabricación, entre otros factores que son considerados en el diseño industrial.

\section{SINÓNIMOS}

Medio, entorno, ambiente.

\section{ANTÓNIMO}

No existe.

\section{EJEMPLOS}

El contexto histórico de un producto se refiere al conocimiento y descripción de sus antecedentes, siempre importantes para evitar la discontinuidad en su evolución tecnológica, estética, cultural, social, etc.

El contexto económico en el diseño industrial es muy importante, ya que a partir de esa descripción es posible conocer la factibilidad y viabilidad de hacer o no un producto.

Hoy en día se da mucha importancia al contexto ambiental en el diseño de productos, debido principalmente al impacto ecológico que puede provocar la producción industrial, así como sus desechos.

Para el diseñador es inevitable conocer y describir el contexto social, debido a que no tendría sentido pensar en el diseño sin conocer las características del grupo social al que se dirige el producto, en este caso es importante saber el poder adquisitivo, las costumbres de consumo, los hábitos, entre otros factores sociales importantes.

\section{Diseño}

\section{Definición Diccionario RAE (DENOTACIÓN)}

(Del it. disegno). Traza o delineación de un edificio o de una figura; proyecto, plan. Concepción original de un objeto u obra destinados a la producción en serie. Forma de cada uno de estos objetos. Descripción o bosquejo verbal de algo. Creación original de un objeto $u$ obra.

\section{DESARROLLO O CONSTRUCCIÓN DEL CONCEPTO}

El diseño consiste en un conjunto de acciones y trabajos de producción cultural a través de la proyectación y producción de objetos y otros componentes de la cultura material.

También puede entenderse como la dirección o plan para llevar a cabo una acción o una idea, lo mismo que la concreción de ese proceso en sus formas específicas.

\section{USOS O ACEPCIONES (ACLARACIONES)}

El término diseño se refiere a la actividad creativa de proyectación de distintos elementos como: objetos, imágenes, tipografías, logotipos, etc.

También se refiere a la representación gráfica de algún objeto o elemento que servirá de modelo y guía para su realización. En otros casos diseño se entiende como la morfología que asume en la realidad la representación de lo diseñado. Finalmente, la explicación breve y esquemática de un plan u objetivo, también es concebida como diseño.

\section{SINÓNIMOS}

Boceto, bosquejo, croquis, esbozo, proyecto, apunte, plan, planteamiento, trazo, esquema. 


\section{ANTÓNIMOS}

Improvisar, desdibujar.

\section{EJEMPLOS}

El pensamiento ordenado y jerarquizado con una intención definida de utilidad es a lo que se define como diseño, sin embargo, también es diseño el resultado de esa acción creativa que produce lo útil, algunos ejemplos de diseño son:

Diseño asistido por computadora, se refiere a una moderna manera de realizar los trabajos de proyecto con el uso de nuevas tecnologías, como son el software y el hardware.

Diseño de proyecto, se refiere a la planeación de las acciones e instrumentos que permitirán llevar a cabo un objeto, una imagen o un espacio.

En el diseño industrial el término se utiliza para definir la producción, planeación y definición de alternativas de solución a un problema que satisfaga alguna necesidad específica, por ejemplo: para sentarse se tienen muchas alternativas posibles, éstas pueden ser una silla, un banco, un sofá, una banca, entre otras; que deberán de tener ciertas características según las condiciones en las que deba llevarse a efecto la acción; si fuera elegida la silla, ésta deberá tener características que resuelvan el problema definido, es decir, podría tener cuatro patas, tres, dos empotradas al suelo, incluso podría tener una pata con una base estabilizadora, asimismo, tener un respaldo fijo o uno móvil y ajustable; todo se tendrá que ir acomodando conforme corra el proceso, eso es lo que se entiende como diseño, pero también lo es el resultado final ya materializado.

\section{Fenómeno}

\section{Definición Diccionario RAE (DENOTACIÓN)}

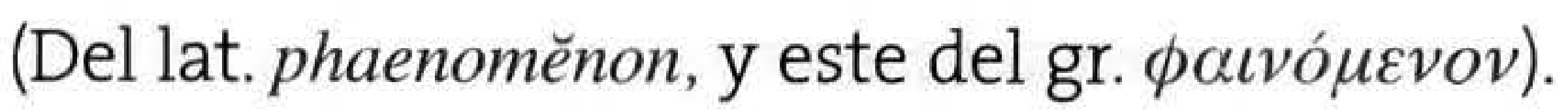
Toda manifestación que se hace presente a la consciencia de un sujeto y aparece como objeto de su percepción. En la filosofía de Immanuel Kant, lo que es objeto de la experiencia sensible.

\section{DESARROLLO O CONSTRUCCIÓN DEL CONCEPTO} Su significado es "lo que aparece", equivale a "apariencia". El mundo de los fenómenos o apariencias es el mundo de las "meras representaciones". Es el acto fáctico del hecho natural sensible, es la vivencia concreta del contexto y los sujetos en el sitio. Es el mundo de las representaciones de las formas sensibles. En ese sentido el fenómeno puede ser materia de descripción y objeto de una fenomenología. El fenómeno es lo que parece ser, tal como realmente se manifiesta contraponiéndose al ser verdadero; el fenómeno no siempre significa lo ilusorio.

\section{USOS O ACEPCIONES (ACLARACIONES)}

"Lo que se hace patente por sí mismo", "lo que es inmediatamente dado".

"Lo que se revela por sí mismo en su luz".

Primera impresión sensible construida de una experiencia.

Fenómeno de estudio. Esta idea está ubicada en el diseño industrial respecto a la noción central de observación y análisis en la localización de una necesidad y la definición de un problema dentro de una realidad dada, por ejemplo: es un fenómeno de estudio para el diseño 
industrial la producción artesanal de objetos de uso cotidiano mediante tecnologías de punta, como son: la estereolitografía y la manufactura láser.

Fenómeno de consumo. Se utiliza en el diseño industrial para determinar los hábitos de compra de una población, por ejemplo: hoy en día una de las formas de compra preferidas es a través del Internet, a tal grado que se ha convertido en un fenómeno.

\section{SINÓNIMOS}

Manifestación, apariencia, revelación, demostración, acto fáctico, el hecho mismo, hecho, suceso, acontecimiento.

\section{ANTÓNIMOS}

No percibido, inaprensible.

\section{EJEMPLOS}

La globalización se ha convertido en un fenómeno de estudio importante para el diseño industrial, debido a que en gran medida los productos que son diseñados y manufacturados en una región, son consumidos en regiones distantes en todo el mundo.

Debido a la globalización que implica la comunicación, traslado de productos y movilidad de las personas, se ha estado formando un fenómeno cultural conocido como: fenómeno cultural de lo híbrido o hibridación de la cultura.

\section{Lenguaje}

\section{Definición Diccionario RAE (DENOtACIÓN)}

Conjunto de sonidos articulados con que el hombre manifiesta lo que piensa o siente. Manera de expresarse. Lenguaje culto, grosero, sencillo, técnico, forense, vulgar. Estilo y modo de hablar y escribir de cada persona en particular. Conjunto de señales que dan a entender algo. El lenguaje de los ojos, el de las flores. En informática conjunto de signos y reglas que permiten la comunicación con un ordenador.

\section{DESARROLLO O CONSTRUCCIÓN DEL CONCEPTO}

En general, el uso de los signos intersubjetivos. Por intersubjetivos se entienden los signos que hacen posible la comunicación. Por uso se entiende: 1) La posibilidad de elección (institución, mutación, corrección) de los signos; 2) La posibilidad de combinar tales signos en modos limitados y repetibles. Ya sea natural (histórico), artificial (diseñado) o una mezcla de ambos, el lenguaje está constituido de signos convencionales. Dado que cada signo debe elucidarse en términos de otros símbolos, los signos aislados no son significantes.

\section{USOS O ACEPCIONES (ACLARACIONES)}

Lenguaje objeto: empleado para referirse a elementos no lingüísticos.

Metalenguaje: utilizado para referirse a expresiones de un lenguaje objeto, es decir, para "hablar" del lenguaje.

Concepción pictórica del lenguaje: la postura de que los lenguajes representan al mundo. 
Lenguaje como instrumento que permite el pensamiento, así como el ordenar el caos del universo. Cabe mencionar que el universo humano sólo existe a partir de esta operación de orden mediante el lenguaje.

En el campo del diseño industrial los distintos lenguajes utilizados van desde el hablado y el escrito, hasta el dibujado, que pueden tener connotaciones diferentes como son: lo técnico, lo científico, lo disciplinario, lo cotidiano, etc., por ejemplo: el dibujo técnico es un lenguaje que usan las personas que están involucradas en el desarrollo tecnológico, mismo que tiene sus reglas y normas propias.

\section{SiNóNIMOS}

Idioma, habla, glosario, lengua, lexicón o léxico.

\section{ANTÓNIMO}

No existe.

\section{EJEMPLOS}

Lenguaje como sistema de signos lingüísticos.

Lenguaje formal: en el caso del diseño industrial, la estética forma la base del lenguaje formal para desarrollar la composición armónica del producto.

\section{Lenguaje fotográfico.}

Lenguaje cinematográfico.

Lenguaje oral.

Lenguaje escrito.

\section{Objetivo}

\section{Definición Diccionario RAE (DENOtACIón)}

Significa echar adelante, ofrecerse, exponerse a algo, presentarse a los ojos. En sentido figurado objetivo significa proponer, causar, inspirar (un pensamiento o sentimiento), oponer (algo en defensa propia), interponer.

Los objetivos son términos de presunciones o presuposiciones y de juicios, los cuales "apuntan a" o "mientan" aquello de lo cual hablan, son presupuestos o juzgados. Definimos al objetivo como adjetivo referido a cualidades $o$ accidentes.

\section{DESARROLLO O CONSTRUCCIÓN DEL CONCEPTO}

El objetivo establece las directrices que guían y acotan el trabajo del diseñador industrial.

\section{USOS O ACEPCIONES (ACLARACIONES)}

El diseño industrial, al igual que otros campos del diseño, se encuentra en proceso de definición de términos, dimensiones, propósitos que delimiten su quehacer y personalidad. Al hacer referencia al objetivo del diseño industrial, nos encontramos con una multiplicidad de interpretaciones sujetas a temporalidades, escuelas, tendencias, modas y, en conjunto, con la concepción macroestructural definida por la cultura.

\section{SINÓNIMOS}

Meta, finalidad, propósito, intención, destino, ideal, fin, llegar a... 


\section{ANTÓNIMOS}

Indefinido, truncado, fragmentario, sin dirección, deficiente, inacabado, subjetivo, parcial.

\section{EJEMPLOS}

La resolución de un problema proyectual.

La construcción o producción de un satisfactor (objeto - producto).

La definición y cumplimiento de requerimientos de diseño.

\section{Objeto}

\section{Definición Diccionario RAE (DENOtACIÓN)}

(Del lat. obiectus). Todo lo que puede ser materia de conocimiento, sensibilidad o asunto al ejercicio de las facultades mentales de parte del sujeto, incluso este mismo. Cosa material e inanimada, generalmente de tamaño pequeño o mediano, artículo, cuerpo, producto, cachivache.

\section{DESARROLLO O CONSTRUCCIÓN DEL CONCEPTO}

Constituye uno de los factores objetivos del proceso de reproducción social. Esto es, uno de los componentes de la peculiaridad del sujeto en el proceso humano de vida que se caracteriza por tener una socialidad que es maleable.

Genéricamente, el objeto (el bien producido u objeto práctico) como factor objetivo del proceso de reproducción social, está compuesto de dos versiones, en una, se encuentra en su estado simple, y en la otra en su estado desarrollado.

El objeto producido para el disfrute humano y por el trabajo humano presenta una gran singularidad, pues su forma es configurada, y por tanto concreta, única, es decir, no general o abstracta. Pero, al mismo tiempo, es capaz de cambiar de configuración no sólo de una situación histórico-concreta a otra, sino incluso de un episodio de producción o disfrute a otro.

\section{USOS O ACEPCIONES (ACLARACIONES)}

Objeto es toda cosa con carácter material e inanimado, también es objeto toda persona o cosa a la que se dirige una acción o pensamiento. Objeto es la materia de estudio de una ciencia; y también lo es el fin al que se dirige una acción.

\section{SiNóNIMOS}

Cosa, elemento, cuerpo, ente, pieza, finalidad, propósito, objetivo, fin, intención.

\section{ANTÓNIMOS}

Informe, desagregado, incierto, sin dirección, carente de intención.

\section{EJEMPLOS}

Arquitectura de objetos.

Arquitectura orientada a objetos.

Detector de objetos metálicos.

Diseño jerárquico orientado a objetos.

Diseño orientado a objetos.

Distancia medida alrededor de un objeto.

Empaquetador de objetos.

Lenguaje orientado a objetos.

Permanencia de un objeto.

Relacionado con objetos.

Relaciones de objeto. 
Sistema de gestión de objetos.

Sistema de programación orientado a objetos.

\section{Relación}

\section{Definición Diccionario RAE (Denotación)}

(Del lat. relatio, -ōnis). Exposición que se hace de un hecho. Conexión, correspondencia de algo con otra cosa, trato, comunicación de alguien con otra persona. Lista de nombres o elementos de cualquier clase. Informe que generalmente se hace por escrito y se presenta ante una autoridad. En matemáticas, resultado de comparar dos cantidades expresadas en números.

\section{DESARROLLO O CONSTRUCCIÓN DEL CONCEPTO}

El término relación nombra a una realidad, pero a una realidad que no es en sí, sino en otro, para que la relación sea es indispensable que previamente sean los polos, los extremos de la relación, sin ellos no hay relación.

La relación no es una sustancia a la que compete ser en sí, sino que es un accidente al que compete el ser, pero en otro. La relación como accidente, tiene su existencia peculiar en el ser de los polos. El ser real de una relación depende del ser real de las cosas que se relacionan.

En toda relación hay una dirección, que es la recta que une a los polos, en esa dirección se presentan los dos sentidos de la relación, en ella se apunta o a un extremo o al otro; o se va o se viene.

La dirección y el sentido determinan a la relación; es en los polos de la relación en los que se determina la dirección y es en los polos también que se descubre el apuntar a... de uno al otro.

La idea de relación es la idea de una categoría fundamental en el pensamiento humano ya que el ser del hombre es relación y por consiguiente su pensamiento es relación. Sin relación no se piensa, ni el hombre, ni la sociedad, ni el mundo. Todo hombre es su ser y sus relaciones.

La relación es principio del orden; ella introduce el orden en la multiplicidad absoluta que es el caos, la cual es impensable, y la convierte en cosmos, en universo; la unifica y la hace racional.

El orden es principio de toda relación, por eso cuando se piensa relacionando se encuentra la lógica de las cosas, de los fenómenos de la realidad que antes se encontraban en el caos.

\section{USOS O ACEPCIONES (ACLARACIONES)}

La multiplicidad de relaciones concretas pueden clasificarse al introducir entre ellas relaciones que hagan posibles los criterios de tipificación. Así, se habla de relaciones reales y relaciones de razón y en esa clasificación se tomó como criterio la relación con el ser: se habla de relaciones reales cuando se relacionan con el ser y se ve que se siguen del ser de los polos, como serían las relaciones entre padre e hijo o entre el agua y el ente vivo; además, se dice que hay relaciones mixtas, reales por un lado y lógicas por otro, como la relación del conocimiento, que es relación entre el pensar y el ser y, también la relación de identidad, que es la relación de uno consigo mismo.

En el diseño industrial se pueden localizar muchas formas de relación, están por ejemplo las de carácter estético, en donde uno de los polos es la 
percepción del ser humano, cargada de una gran cantidad de antecedentes culturales, como son los hábitos, las costumbres y las tradiciones, y también repletas de factores fisiológicos, como es la sensibilidad, o también componentes psicológicos experimentados en las emociones; mientras que el polo opuesto está ubicado en las cosas, en los objetos naturales $\mathrm{o}$ artificiales que poseen de manera inherente caracteristicas expresivas y significativas, o también otorgadas por los diseñadores intencionalmente, es decir, cuando la persona ve, escucha, palpa, huele o saborea algo, se establece un continuo ir y venir de energía, información o signos que se transforman en significados y dan sentido al acontecer, se establece un orden entre aquello que debe significar porque tiene una intención y lo que se percibe y se razona para generar nuevas relaciones con otras cosas.

\section{SINÓNIMOS}

Referencia, correlación, correspondencia, vínculo, nexo, ligazón, ilación, concomitancia, concordancia.

\section{ANTÓNIMOS}

Desconexión, independencia.

\section{EJEMPLOS}

En términos generales existen muchos tipos de relaciones, se encuentran por ejemplo: las relaciones laborales, las relaciones familiares, las relaciones amorosas, las relaciones comerciales, las relaciones internacionales y más que pueden escucharse de manera cotidiana en distintos espacios.
En el ejercicio del diseño industrial también existen muchos tipos de relaciones, se encuentran las relaciones entre la forma del objeto y su uso, aquí se pueden citar por ejemplo: los vínculos existentes entre una superficie destinada a la acción de sujetar con las manos, con las distintas posiciones, dimensiones y sensibilidad de las manos mismas; si existe una relación correcta entre las superficies de sujeción y las manos del usuario, el resultado puede ser la comodidad, la seguridad e incluso el agrado.

Otro ejemplo podemos ubicarlo en la función que debe desempeñar cada una de las partes componentes del objeto, como en el siguiente caso: si una pieza componente de un envase debe sellar o provocar la hermeticidad, la relación funcional está condicionada a la dureza o suavidad de los materiales involucrados en la condición funcional, también depende de los acabados superficiales (lisura o aspereza) entre las partes involucradas; otro elemento que debe ser considerado en la relación es la densidad y la composición química del contenido, no será lo mismo que el sello soporte una densidad y química del agua, que la de un aceite $o$ algún solvente como el tiner, la gasolina o el aguarrás.

\section{Sujeto}

\section{Definición Diccionario RAE (DENOtACIÓN)} Expuesto o propenso a algo. Asunto o materia sobre el que se habla o escribe. Persona innominada. Frecuentemente cuando no se quiere declarar de quién se habla, o cuando se ignora 
su nombre. En filosofia, espíritu humano, considerado en oposición al mundo externo, en cualquiera de las relaciones de sensibilidad o de conocimiento, y también en oposición a sí mismo como término de conciencia. También, ser del cual se predica o anuncia algo. En gramática, función oracional desempeñada por un sustantivo, un pronombre o un sintagma nominal en concordancia obligada de persona y de número con el verbo. Pueden ser también cualquier sintagma o proposición sustantivada, con concordancia verbal obligada de número en tercera persona.

\section{DESARROLLO O CONSTRUCCIÓN DEL CONCEPTO}

Desde el punto de vista lógico, sujeto es aquello del que se afirma o niega algo. Desde el punto de vista ontológico, el objeto sujeto. Desde el punto de vista gnoseológico, el sujeto es el sujeto cognoscente, el que es definido como sujeto para un objeto en virtud de la correlación sujeto-objeto que se da en todo fenómeno de conocimiento y que hace imposible la exclusión de uno de los elementos.

Con base en la Enciclopedia Universal, la definición más básica se refiere al asunto 0 materia sobre el que se habla o se escribe, se puede agregar sobre el personaje al que está dirigido el diseño, o sobre el que hace la acción de diseñar. En términos filosóficos, el sujeto se encuentra dentro de múltiples significaciones, enmarcadas en lo verbal, lo lógico y lo real, por este motivo se ubica dentro de la gramática, en la dialéctica y la ontología. Su caracterización diferencia lo objetivo de lo subjetivo, siendo lo primero lo que se encuentra en el pensamiento, frente a lo que está en las cosas mismas.

\section{USOS O ACEPCIONES (ACLARACIONES)}

Como diferenciador de los objetos, complemento lógico de la relación de conocimiento entre sujetos (quien realiza la acción) sobre los objetos (sobre quienes es realizada la acción).

El usuario es el sujeto central del diseño.

Eluso más común que se le da al término sujeto en el ejercicio del diseño industrial se define como la persona innominada. Así, en lugar de nombrar a "Juan Pérez", por decir alguien en específico, el diseñador se refiere al usuario como el sujeto que tendrá una interacción directa con el objeto, o también se le nombra sujeto a, la o las personas que patrocinan el proyecto, asimismo, se encuentran en esta categoría los clientes que pagarán por el producto, o los mismos diseñadores.

El término sujeto en el diseño industrial facilita el manejo de la información ya que generaliza; sería imposible, además de inoperante, relacionar a cada uno de los productos diseñados con cada una de las personas destinadas a hacer uso o a comprar el objeto; eso sólo podría darse en la elaboración de una obra de arte o incluso en el trabajo artesanal, es decir, una pintura, una melodía o una composición poética puede ser realizada por encargo de alguien en particular o inspirada en alguien en particular, o en el caso de las obras artesanales: un comedor, una silla o una pieza de joyería está generalmente realizada por un encargo particular de alguien que satisfará sus expectativas y exigencias con piezas únicas. 


\section{SINÓNIMOS}

Persona, individuo, tipo, fulano, hombre, ente, yo, entidad.

\section{ANTÓNIMOS}

Independiente, liberado, libre, sociedad.

\section{EJEMPLOS}

Sujeto empírico, sujeto de estudio, sujeto de conocimiento, sujeto de investigación, sujeto de diseño, entre otros.

En particular dentro de la disciplina del diseño industrial se localizan como sujetos a los distintos usuarios y clientes involucrados con la interacción y operatividad del producto; así en lugar de nombrar al operador de la máquina que lo fabricará, al ensamblador, al que lo transportará, el que lo distribuirá, al que lo observará en el aparador, a quien le dará el mantenimiento, incluso a quien lo recuperará cuando su vida útil haya finalizado, se menciona de manera genérica al sujeto usuario, sujeto de convencimiento para la venta, sujeto para la recuperación de los materiales, etc.

\section{Teoría}

\section{DEFINICIÓN Diccionario RAE (DENOTACIÓN)}

Theoria, significa mirar, observar, ver, contemplar. En teoría del conocimiento y en filosofía de la ciencia se ha discutido con frecuencia el sentido que puede darse a la teoría: la relación entre la noción de teoría y las nociones de principio, hipótesis, ley; la naturaleza y estructura de las teorías científicas; la relación entre teoría y hechos; las interpretaciones que pueden darse de las teorías; las relaciones entre teorias en las ciencias naturales con teorías en las ciencias sociales y teorías de la cultura.

Teoría es un cuerpo coherente de conocimientos sobre un dominio de objetos; cuando este cuerpo de conocimiento es formalizado, se origina una teoría axiomática.

\section{DESARROLLO O CONSTRUCCIÓN DEL CONCEPTO}

La teoría se puede entender como: las posturas e interpretaciones generadas en la cultura para la comprensión y construcción de un objeto de estudio. Entendida la cultura como toda manifestación del quehacer y pensamiento humano.

\section{USOS O ACEPCIONES (ACLARACIONES)}

La teoría permite la comprensión del mundo y de sus realidades a través de los distintos campos creados para la comprensión y transformación del mundo todo, por ejemplo, en el campo de las ciencias formales, experimentales, sociales y de la cultura en general.

En el campo del diseño industrial el uso de la teoria está enfocado fundamentalmente a funcionar como el principal soporte de entendimiento y explicación de los fenómenos de ciencia, tecnología y arte relacionados con el diseño de productos fabricados de manera industrial, así entonces, se enfocan teorias de la estética, teorias de los sistemas, teorias de la cibernética o teorías del comportamiento de la sociedad y la cultura que permiten explicar y explicarse los diferentes fenómenos acontecidos o por acontecer 
antes, durante y después del diseño del producto, por ejemplo: ¿cómo explicar desde la perspectiva del diseño industrial el fenómeno de la sustentabilidad?, de manera tal que sea posible proyectar objetos respetuosos del medio ambiente, compatibles con el desarrollo económico y éticamente fundados en una cultura del aprovechamiento, entre otros aspectos.

\section{SINÓNIMOS}

Suposición, creencia, hipótesis, conjetura, probabilidad, especulación.

\section{ANTÓNIMOS}

Práctica, pragmatismo.

\section{EJEMPLOS}

En el campo de las ciencias formales se encuentran, por ejemplo: la teoría de conjuntos y la teoría de sistemas.

En el caso específico del diseño industrial se localizan: la teoría de las necesidades, que está basada en una teoría del proyecto, considerando al análisis de la acciones del usuario en una situación de carencia o de inexistencia de algún medio o elemento físico material y/o perceptual de satisfacción como el componente fundamental del desarrollo y ejecución del proyecto y, por tanto, del diseño.

Otro ejemplo estaría en la teoría de la forma, ésta recae en la idea contenida en los fenómenos de la percepción, de un sujeto estimulado por las relaciones establecidas con el mundo material, a través de su percepción cultural.

Otro ejemplo más está ubicado en las teorías de la comunicación. Se dice que todo objeto de diseño debe comunicar, es decir, poner en común una cierta información que signifique algo a alguien, así se encuentra en este terreno la teoría de medios, la teoría situacional, la teoría estructuralista, entre otras, que sirven para explicar y explicarse el por qué, un producto se debe promover de una manera particular, o cómo debe dirigirse una cierta campaña publicitaria, o también lo que significa que el producto tenga un cierto tamaño, color, o figura particular que va dirigido a un cierto grupo social. 


\section{Bibliografía}

AbBagnano, Nicola (2008), Diccionario de filosofia, México: Fondo de Cultura Económica.

BUNGE, Mario (2007), Diccionario de filosofia. México: Siglo XXI.

BÜRDEK, Bernhard (1994). Diseño.

Historia, teoria y práctica del diseño

industrial, Barcelona: Gustavo Gili.

Diccionario de la Real Academia

Española de la Lengua.

(2005), Diccionario de sinónimos y

antónimos, Espasa-Calpe.

(2009), Diccionario Enciclopédico Vox

1. Larousse Editorial, S. L.

(2007), Diccionario Manual de la Lengua

Española Vox. Larousse Editorial, S. L.

(2007), Diccionario Manual de Sinónimos

y Antónimos de la Lengua Española

Vox, Larousse Editorial, S. L.

ECHEVERRÍA, Bolívar (2001), Definición de

la cultura, México: UNAM-Itaca.

Enciclopedia Espasa-Calpe.

FERRETER Mora, J. (1999), Diccionario de filosofia, Barcelona: Editorial Ariel.

GARCÍA Olvera, Francisco (1996), Reflexiones sobre el Diseño. México: UAM/ Azc. (Colección CYAD).

- (2001), "Taller Servicio 24 Horas", Revista de investigación, año 3 núm. 6, México, UAM/ Azc.

\section{REFERENCIAS DE INTERNET}

http://buscon. RALE.es/d RALEI/

SrvltConsulta?TIPO_BUS=3\&LEMA=fenómeno

http://definicion.de/analisis/

http://es.thefreedictionary.com/diseño

http://www.diccionariodeantonimos

com/proyectar.html

http://www.etsimo.uniovi.es/dic/anton.cgi

http://www.lenguaje.com/cgi-bin/Tesauro.

exe?T1=objeto http://www.wordmagicsoft.

com/diccionario/es-en/objeto.php

http://www.wordreference.com/sinonimos/diseño 